\title{
Rapid detection of glycerol dialkyl glycerol tetraethers (GDGTs) in marine sediment using FT-ICR MS with different ionization techniques
}

\author{
BIN JIANG AND YUHONG LIAO ${ }^{1 *}$
}

${ }^{1}$ State Key Laboratory of Organic Geochemistry, Guangzhou Institute of Geochemistry, Chinese Academy of Sciences, Wushan, Guangzhou 510640, China (*correspondence: liaoyh@gig.ac.cn)

\section{Introduction}

Glycerol dialkyl glycerol tetraethers (GDGTs) lipids are important membrane constituents of Archaea, ubiquitous microorganisms thought to be limited to extreme environments [1]. GDGTs have potential to be directly detected by Fourier Transform Ion Cyclotron Resonance Mass Spectrometry (FT-ICR MS) with atmospheric pressure photoionization (APPI) source in positive mode [2]. In this study, we characterized and compared the detection of GDGTs extracted in marine sediment using FT-ICR MS with different ionization techniques (ESI+ with or without ammonium formate and APPI+).

\section{Discussion of Results}

In ESI+ mode, some GDGTs compounds with m/z 1292-1309 can be ionized by adding ammonium formate compared with that without adding ammonium formate. Therefore, the addition of ammonium formate can better promote the ionization of GDGTs in ESI+ mode. By comparing the FTICR MS mass spectra in APPI + mode and ESI + mode with ammonium formate, we can found that APPI + mode can ionize the conventional GDGTs compounds (GDGTs 0-8), and $\mathrm{m} / \mathrm{z}$ was between 1292-1310, while ESI + mode can not only ionize the conventional GDGTs compounds, but also detect some undiscovered C88 GDGTs analogs, that the range is $\mathrm{m} / \mathrm{z} 1314-1340$. These compounds have two more carbon atoms than general isoprene like GDGTs compounds, which has not been reported in the literature.

[1] F. Omar Holguin and Tanner Schaub (2014). Algal

Research 2, 43-50. [2] JagošR. Radović et al. (2015)

Analytical Chemistry 88, 1128-1137. 